\title{
A Falácia do Paradoxo: Uma Análise do Binômio Risco-Retorno no Mercado de Capitais Brasileiro
}

\author{
Vagner Antônio Marques ${ }^{(i)}$, Bethânia Mara Lima Família Costa ${ }^{(i)}$, Mariana Borges Lopes ${ }^{(D)}$, Sarah Waichert \\ Ramos
}

Universidade Federal do Espírito Santo. Vitória-ES. Brasil.

\section{$\bigotimes$}

'vagner.marques@ufes.br

2bethaniafamilia@gmail.com

3borges.mariana123@gmail.com

${ }^{4}$ sa.waichert@hotmail.com

Editado por:

Orleans Silva Martins

Paulo Roberto da Cunha

\section{Resumo}

Objetivo: O objetivo do presente estudo foi analisar a existência do Paradoxo de Bowman (PB) no contexto das empresas brasileiras listadas na Brasil, Bolsa, Balcão (B3).

Método: O estudo descritivo, com utilização de dados secundários e com abordagem quantitativa, analisou dados trimestrais, do período de 2008-2018, de 292 empresas listadas na B3 e um total de 9.387 observações firmas/ano.

Resultados: As evidências reforçaram a hipótese de associação positiva entre o risco e o retorno, tanto para proxies de mercado quanto para dados contábeis. Entretanto, verificou-se que incertezas econômicas e/ou normativas podem prejudicar a preditividade dos retornos, resultando em uma relação espúria negativa entre o risco e o retorno. Implicações/Contribuições Os resultados reforçam os pressupostos da moderna teoria de finanças, em especial a ideia de associação positiva entre o risco e o retorno. Contribui para o debate na gestão de carteira de investimentos no contexto brasileiro, utilizando-se, inclusive, de dados contábeis. As evidências têm implicações para os investidores, em especial, os não institucionais e outros agentes econômicos que buscam compreender as variáveis relevantes na tomada de decisão em investimentos de risco.

Palavras-chave: Seleção de Carteiras, Binômio Risco-Retorno, Paradoxo de Bowman.

Como citar:

Marques, V. A., Costa, B. M. L. F., Lopes, M. B., \& Ramos, S. W. (2021). A FALÁCIA DO PARADOXO: UMA ANÁLISE DO BINÔMIO RISCO-RETORNO NO MERCADO DE CAPITAIS BRASILEIRO. Advances in Scientific and Applied Accounting, 14(2), 109-122/123. https://doi.org/10.14392/ asaa. 2021140205 


\section{Introdução}

O objetivo do presente estudo foi analisar a existência do Paradoxo de Bowman (PB) no contexto das empresas brasileiras listadas na Brasil, Bolsa, Balcão (B3). De acordo com Nickel e Rodriguez (2002), o binômio risco-retorno é a base dos modelos de decisão de investimentos e consiste na expectativa ex-ante de que os investidores estarão dispostos a assumirem maior risco caso sejam compensados por isso. Logo, risco e retorno estarão positivamente associados.

Entretanto, Bowman (1980) apresenta evidências de que essa expectativa não se confirma quando analisada a partir de dados contábeis, sugerindo que haja um paradoxo, o qual posteriormente levou o seu nome (Paradoxo de Bowman). Na contradição, o risco e o retorno podem apresentar correlações negativas.

Ocorre que, na perspectiva da Moderna Teoria de Finanças, os investidores são avessos a perdas, e por isso buscam maximizar seus retornos, fazendo com que os ativos sejam precificados a partir do conjunto de informações disponíveis no mercado, incluindo as contábeis (Fama, 1970; Markowitz, 1952). Nesse sentido, as decisões de investimento estarão ancoradas nas informações disponíveis, bem como no risco e no retorno esperado $(\mathrm{Re})$, por vezes estimado a partir do CAPM Capital Asset Pricing Model. Conforme Lintner (1965) e Sharpe (1964), o CAPM considera que o Re é uma função do retorno de um ativo livre de risco (Rf) adicionado de um prêmio pelo risco $(\mathrm{Pr})$ que aumenta quão mais arriscado for o investimento em potencial.

Para Penman (2016), o lucro (prejuízo) apresentado nas demonstrações financeiras é um dado útil para a avaliação e a precificação de ativos. A esse respeito, Johnstone (2021) aponta que, no processo de precificação de ativos, aqueles investidores que conseguirem realizar estimações de retorno esperado mais precisas tendem a obter uma relação risco/retorno mais consistente. Adicionalmente, esse último autor reforça que o conjunto de informações contábeis disponíveis possibilita que os investidores avaliem o risco específico (da firma) de forma mais acurada. $O$ desempenho observado na empresa é comparado com o esperado, logo, ocorrerão ajustes nas premissas utilizadas nos modelos de precificação, em especial, naquelas relacionadas ao risco.

Diante disso, a relação negativa ex-ante entre riscoretorno seria uma associação contraintuitiva, apesar de que seja possível que ex-post ocorra por diversos motivos, destacando-se: (i) vieses cognitivos dos investidores e gestores (Kahneman \& Tversky, 1979; Kliger \& Tsur, 2011); (ii) falha na implementação da estratégia (Holder et al., 2016); (iii) incerteza econômica no contexto da firma (Muñoz et al., 2020); e (iv) nível de competição na indústria (Christensen et al., 2020), entre outros.

Apesar de a literatura de finanças apresentar hipóteses que explicam as causas potenciais da relação negativa entre risco e retorno ex-post, diversos estudos têm sido desenvolvidos em contextos econômicos diferenciados com $\circ$ intuito de analisar em quais condições O PB se confirma (Dimic et al., 2015; Patel et al., 2018; Singh \& Singh, 2017). Em síntese, o PB tem sido reforçado em contextos socioeconômicos adversos e que dificultam a previsibilidade do desempenho futuro da firma (Becerra \& Markarian, 2021). Por exemplo, para empresas que apresentam resultados negativos sistemáticos e inferiores à mediana do setor (Andersen et al., 2007; Henkel, 2009), assim como para empresas com baixa negociabilidade de ações, mas com potencial de crescimento elevado (Chen, 2017).

No contexto brasileiro, a literatura de finanças e contabilidade apresenta evidências mais consistentes de que a relação entre o risco-retorno é positiva, tanto para proxies de mercado quanto contábeis (Amorim et al., 2012; Amorim et al., 2014; Artuso \& Chaves Neto, 2010). Contudo, os trabalhos de Silveira (1990) e Vieira (2012) buscaram analisar especificamente o PB e encontraram resultados que sustentam a relação negativa entre risco-retorno a partir de dados contábeis. Outros trabalhos mais recentes encontraram relações inversas ou não significativas, embora as explicações dadas não se ancorem nas propostas do PB (Mikosz et al., 2020; Perobelli et al., 2016; Pimentel, 2015).

Diante das divergências observadas na literatura nacional, o presente estudo buscou responder a seguinte pergunta: Qual a associação entre o risco e o retorno a partir de dados contábeis e de mercado no contexto das empresas brasileiras listadas? $O$ estudo descritivo, com utilização de dados secundários e com abordagem quantitativa, analisou dados trimestrais, do período de 2008-2018, de 292 empresas listadas na B3 e um total de 9.387 observações firmas/ano.

Esta pesquisa se diferencia das desenvolvidas anteriormente no contexto brasileiro, porque utiliza um conjunto de dados trimestrais, que captura a variabilidade do mercado ao longo dos trimestres e anos, e analisa a 
associação contemporânea e defasada entre as proxies de risco-retorno contábil e de mercado. O estudo utiliza ainda uma abordagem metodológica mais consistente que a utilizada por Silveira (1990) e Vieira (2012), que sugerem a existência do PB.

Além disso, o estudo apresenta evidências de que a análise da relação entre o retorno das ações e o risco, mensurado a partir de métricas contábeis, deve considerar a existência de uma relação defasada entre elas, a qual é ajustada ao longo dos trimestres, mediante a divulgação das informações financeiras trimestrais. Logo, os resultados dos estudos anteriores nacionais que analisaram a associação contemporânea podem ter observado inexistência de relação ou, ainda, a inversão dos sinais em decorrência de efeitos espúrios. Por fim, o estudo apresenta evidências de relação positiva entre risco e retorno no contexto brasileiro, mas indica que fatores como incerteza econômica e regulatória, estrutura do setor e estágios do ciclo de vida da firma podem inverter essa relação, conforme destaca Henkel (2009).

Do ponto de vista empírico, os resultados fragilizam a hipótese de que exista um paradoxo na relação ex-ante do binômio risco-retorno. Logo, continua sendo uma premissa aplicável no processo de avaliação e tomada de decisão de investimentos no mercado de capitais brasileiro. Os resultados reforçam o papel dos números contábeis como mecanismo de ajuste das expectativas quanto aos retornos esperados, já que a relação positiva observada é coerente com as bases do CAPM. Além disso, demonstra que características setoriais e/ou da firma podem influenciar na relação risco-retorno, sugerindo de forma falaciosa que exista um paradoxo. Nesse contexto, gestores de carteiras, investidores institucionais e não institucionais, entre outros agentes econômicos, podem se beneficiar dos resultados apresentados.

\section{Revisão da Literatura}

\subsection{Relevância da Informação Contábil no Contexto da Precificação de Ativos}

De acordo com Kothari (2001), a relevância da informação contábil configura uma linha de pesquisa que tem se desenvolvido desde os trabalhos de Ball \& Brown (1968) e Beaver (1968), os quais analisaram a relevância dos números contábeis para o mercado de capitais. Contudo, nas últimas décadas tem havido mudanças nas métricas utilizadas pelos investidores para análise, previsão e tomada de decisão sobre a alocação de recursos (Barth et al., 2021).
Apesar disso, o papel confirmatório da informação contábil se manteve, pois, diferente de outras fontes de informação financeira, as normas de reconhecimento, mensuração e divulgação fazem da contabilidade um mecanismo que possibilita os diversos usuários ajustarem suas expectativas quanto ao desempenho e fluxos de caixa futuros da firma, precificando de forma mais acurada os riscos e retornos esperados (Paolone, 2020).

De acordo com Markowitz e Dijk (2008), no processo de estruturação de portfólio e gestão de riscos, a adequada apropriação das informações disponíveis sobre os ativos possibilita que a avaliação do risco-retorno seja mais acurada, pois o retorno esperado $\left(R_{e}\right)$ é uma função do retorno de um ativo livre de risco $\left(R_{f}\right)$ adicionado do prêmio pelo risco assumido $\left[\beta_{a}\left(R_{m}-R_{f}\right)\right]$. Nessa equação, o risco é mensurado a partir da volatilidade do ativo em relação à volatilidade do mercado (risco sistemático) (Chen, 2017).

Acontece que esse processo de precificação é realizado a partir dos dados históricos e correntes, antes da ocorrência do investimento e/ou apresentação do resultado efetivo da empresa, pois se está falando em estimar o retorno esperado (potencial), ou seja, o desempenho futuro. Por exemplo: para precificar o ativo da Cia X, hoje, utiliza-se dos dados disponíveis sobre o seu desempenho (participação de mercado, estratégia, retornos observados sobre os ativos, patrimônio líquido e outros direcionadores de valor etc.), mas não se sabe se a empresa apresentará, no futuro, o desempenho observado até o momento, que sustenta o valor estimado (hoje) e o preço pago por ele.

Para Markowitz e Dijk (2008), o investidor, enquanto um indivíduo avesso a perdas, estará disposto a pagar mais por um ativo arriscado se, e somente se, receber um maior prêmio pelo risco. Porém, isso não garante que, ex-post, os retornos observados $\left(\mathrm{R}_{\mathrm{i}}\right)$ sejam iguais ou superiores aos esperados $\left(R_{\mathrm{e}}\right)$, pois, por exemplo, o desempenho da firma pode ser inferior ao que o mercado esperava, resultando em um retorno observado inferior ao esperado. Mesmo tendo sido apresentado um risco ex-ante maior, essa é uma relação ex-post, que pode ocorrer por diversos motivos.

Na perspectiva da Teoria do Prospecto, de Kahneman e Tversky (1979), a premissa de racionalidade ilimitada das finanças clássicas não considera que os indivíduos se apropriem de forma heterogênea das informações disponíveis. Além disso, existem vieses cognitivos (excesso de confiança, vieses de disponibilidade, ancoragem etc.) que influenciam tanto na avaliação dos dados disponíveis quanto na tomada de decisão, o que pode implicar em erro de julgamento e na tomada de decisão. A Teoria do Prospecto 
é, inclusive, a mais utilizada para a explicação do PB (Nickel \& Rodriguez, 2002).

Outra explicação possível para um retorno inferior em relação ao esperado se refere às condições econômicas e de mercado em que a firma atua. De acordo com Muñoz et al. (2020), o ambiente econômico pode influenciar em erro de estimação (ex-ante) ou em desempenho abaixo do esperado (ex-post). Nessas condições, a tendência é de que o retorno superior esperado em ativos de alto risco não se confirme. Por sua vez, Henkel (2009) observou que as características da distribuição do desempenho das firmas em cada setor explica, em grande medida, a ocorrência do chamado PB, pois em setores onde existe uma distribuição assimétrica à esquerda (predominância de resultado abaixo da mediana), o binômio risco-retorno sofre os efeitos de uma relação espúria e não explicada na literatura. Além disso, nos segmentos econômicos em que a previsibilidade do desempenho é menor, é possível que a relação risco-retorno se inverta, pois resultará em um erro de estimação elevado, sugerindo a existência de um paradoxo.

Outra explicação para a existência de um desempenho além ou aquém do esperado decorre do nível de negociabilidade das ações da firma e do seu potencial de crescimento (Chen, 2017). Nesse sentido, determinadas empresas podem apresentar baixo nível de negociabilidade (liquidez) e possuir potencial de crescimento não identificado pelo mercado (a recíproca é verdadeira). Logo, haveria nesse contexto empresas com baixo risco (assumindo-se preço relativamente constante) e com retorno ex-post muito superior, o que sugeriria a existência do PB. Entretanto, se o investidor potencial realiza a avaliação assumindo possibilidade de risco envolvido, o retorno esperado será maior ou menor, segundo a regra do binômio risco-retorno, mas não necessariamente é o que acontecerá. Dessa forma, nesse cenário, à medida que novas informações são disponibilizadas, os agentes econômicos ajustarão suas premissas para melhorar a acurácia de seus modelos.

\subsection{Existe Mesmo um Paradoxo? Evidências Anteriores Sobre a Relação Risco-Retomo}

A discussão sobre a relação risco-retorno está no cerne das tomadas de decisão sobre investimento e financiamento, mas foi a partir dos trabalhos de Markowitz (1952), de Modigliani e Miller (1963), de Sharpe (1964) e de Lintner (1965) que as pesquisas sobre 0 tema se intensificaram. Fabozzi et al. (2002) destacam que, no contexto da gestão de risco e seleção de portfólio, apesar dos investidores atuais possuírem opções e ferramentas sofisticadas, a proposta de otimização do portifólio a partir da diversificação ainda é predominante. Nessa perspectiva, os investidores buscarão avaliar e decidir sobre a alocação de recursos buscando maximizar o retorno esperado e reduzir o risco da carteira.

Para isso, os investidores buscarão se apropriar do conjunto de informações disponíveis sobre as firmas analisadas de forma que possam estimar, com maior acurácia, os retornos esperados dos investimentos em potencial (Kothari, 2001). Considerando que o risco é mensurado, em geral, a partir da volatilidade de uma métrica de retorno (ex.: retornos das ações, lucros, dividendos, retorno sobre os ativos, retorno sobre o patrimônio líquido etc.), à medida que se observa maior risco, os investidores incorporarão direta ou indiretamente em seus modelos de avaliação através do custo médio ponderado do capital. Fernandez et al. (2021) têm realizado um levantamento anual sobre o custo do capital considerado nos processos de avaliação de empresas em diversos países e as evidências encontradas reforçam que países com maiores incertezas políticas, econômicas e sociais tendem a apresentar maior custo médio ponderado do capital, porque os investidores incorporam em seus modelos as incertezas acerca do desempenho esperado para os ativos analisados.

Nesse contexto, Shum e Tang (2010) buscaram analisar a relação do binômio risco e retorno em empresas listadas do Brasil, Rússia, Índia, China e África do Sul no período de 2003 a 2007. Os autores observaram uma relação positiva entre $\circ$ risco e o retorno, conforme esperado, e destacam que China e Brasil tendem a apresentar, de forma mais consistente, um prêmio pelo risco superior. Os resultados foram consistentes para diferentes proxies de risco utilizadas.

Utilizando uma análise de séries temporais, Chiang et al. (2015) analisaram dados de países emergentes e desenvolvidos e reforçaram as evidências de que existe uma relação positiva entre risco e retorno, incluindo o Brasil, em especial, em momentos de estabilidade econômica. Esse resultado foi observado também por Singh e Singh (2017). Contudo, Bortoluzzo et al. (2014) haviam observado que, no período de 2003 a 2007, não se verificou uma associação positiva entre o risco e o retorno. Segundo estes autores, outros fatores explicariam, de forma mais consistente, o retorno das ações no mercado brasileiro, tais como tamanho, book-to-market, liquidez dos ativos, entre outros. A despeito desse quadro observado, Val et al. (2014) apontam que a utilização de dados de alta frequência pode melhorar a estimação do risco e o retorno, o que reforçaria a expectativa de associação positiva entre o risco e o retorno.

As evidências que reforçam a associação positiva são diversas, porém, fatores que provocam relações espúrias (Gospodinov et al., 2017), como, contexto econômico 
(Salvador, 2012), volatilidade da taxa de câmbio (Ely, 2015), efeito intertemporal da série (Singh \& Singh, 2016), entre outros, podem fragilizar a previsibilidade do risco e o retorno esperado e, portanto, a relação positiva ex-post pode não se confirmar. Diante dessas evidências, analisou-se a seguinte hipótese de pesquisa:

$H_{1}$ : Existe uma associação positiva entre o Coeficiente Beta e o Retorno das ações das empresas brasileiras listadas.

Apesar da análise do risco e retorno, a partir de dados de mercado, reforçar a relação positiva esperada, os resultados a partir de dados contábeis ainda são controversos. Em parte, essa controvérsia se justifica, pelo fato de que, além de concorrer com diversas outras fontes de informação, - modelo contábil não incorpora nas demonstrações financeiras uma série de eventos que são precificados pelo mercado (O'Regan, 2015). Essa prática, evita, por um lado, problemas de incorporação de vieses dos agentes econômicos nas demonstrações contábeis, haja vista as incertezas envolvidas no processo de reconhecimento e mensuração. Por outro, prejudica a capacidade dos números contábeis explicarem o valor de mercado das empresas (Barth et al., 2021). Contudo, Gregoire e Martineau (2021) observam que a informação contábil funciona como um mecanismo de ajuste de expectativas e, portanto, a cada divulgação ocorre a alteração no preço e/ou no volume de negociação das ações. Jia et al. (2020) reforçam que as informações contábeis minimizam os vieses de otimismo e pessimismo que comumente podem ser vistos no mercado de capitais, sobretudo, em momentos de incerteza econômica.

De acordo com Nickel e Rodriguez (2002), existe uma extensa literatura que buscou analisar a existência do PB. Por sua vez, a literatura sobre avaliação de empresas (valuation) tem reforçado a utilidade dos números contábeis na precificação de ativos, além de sustentar que os números contábeis constituem-se dos fundamentos para a precificação de ativos, logo, a relação entre risco e retorno segue ao previsto pela Teoria de Finanças (Lewellen, 2010; Penman, 2011).

Penman e Zhu (2014) demonstram que a expectativa de crescimento dos lucros é a conexão entre o risco de mercado e o risco da firma. Nessa perspectiva, analisando dados de 1962 a 2009, os autores observaram que existe uma associação entre a taxa de crescimento do lucro e o retorno esperado, o que reforçaria a relação positiva entre o risco e o retorno. Lyle et al. (2013) observaram, a partir do modelo de Ohlson, que apesar de encontrarem uma associação positiva entre o custo do capital e o retorno esperado, choques econômicos afetam o risco sistemático e invertem a associação entre o risco e o retorno. Konchitchki et al. (2016) corroboram esse achado e ressaltam que a maior volatilidade dos lucros e risco de falência estão associados a maior expectativa de retorno futuro da firma. Outros trabalhos reforçam a hipótese de que proxies de risco/retorno a partir de dados contábeis estão associados às proxies de mercado e que, portanto, seguem a relação esperada do binômio (Werneck et al., 2010; Amorim et al., 2012, 2014; Araújo \& Machado, 2018; Campos et al., 2014; Giner \& Reverte, 2006; Lopes \& Alencar, 2010; Marinho et al., 2013; Martinez \& Castro, 2011; Souza Filho et al., 2017). Diante dessas evidências, buscou-se analisar a seguinte hipótese:

\section{$\mathrm{H}_{2}$ : Existe uma associação positiva entre o Coeficiente de Variação do Retorno sobre o Patrimônio Líquido (ROE) e o ROE das empresas brasileiras listadas.}

Entretanto, alguns estudos não confirmam a informatividade dos números contábeis na explicação dos retornos esperados das firmas (Mikosz et al., 2020; Muñoz et al., 2020; Perobelli et al., 2016; Pimentel, 2015). Esses resultados adversos quanto à relação risco e retorno têm reforçado a literatura sobre $\circ$ PB e explicam esse paradoxo como decorrentes de vieses cognitivos, problemas metodológicos e erros na implementação de estratégia (Nickel \& Rodriguez, 2002). Diante das controvérsias, visando analisar a associação entre as proxies de risco, a partir de dados contábeis e o retorno de mercado, verificou-se a seguinte hipótese:

$\mathrm{H}_{3}$ : Existe uma associação positiva entre o Coeficiente de Variação do ROE e o Retorno das ações das empresas brasileiras listadas.

\section{Procedimentos Metodológicos}

A pesquisa descritiva, com utilização de dados secundários e com abordagem quantitativa analisou dados trimestrais do período de 2008-2018. Os dados foram obtidos na ComDinheiro e, complementarmente, no sítio eletrônico da B3. Especificamente, os dados sobre os retornos das ações foram extraídos das cotações diárias do período de 31/12/2007 a 31/03/2019, disponíveis no sítio eletrônico Yahoo Finance. A amostra foi composta por 9.387 observações empresa/ano referentes a 292 empresas listadas, excluídas aquelas classificadas no setor financeiro em decorrência da diferença em sua estrutura financeira quando comparadas com as demais.

As variáveis quantitativas foram winsorizadas entre $1 \%$ e $99 \%$ para reduzir o efeito de dados influentes. Como técnica de análise, utilizou-se a regressão com dados em painel. Para a escolha do tipo de painel, foram realizados os testes de Chow, Breusch-Pagan e Hausman, contudo, optou-se pela utilização do modelo de dados em painel com efeitos 
aleatórios em decorrência da manutenção do controle setorial que, nesta discussão, é essencial, haja vista as evidências já observadas por Andersen et al. (2007) e Henkel (2009). Os resultados com a utilização dos demais tipos de painel e outras especificações foram discutidos nos testes de robustez e buscaram avaliar a consistência dos resultados para diferentes especificações.

\subsection{Modelos e Variáveis}

Para se analisar as hipóteses de pesquisa foram utilizados os modelos apresentados nas equações 1, 2 e 3 . Os respectivos modelos consideraram que os retornos correntes são explicados pelas proxies de risco e retorno de mercado (Beta) e contábil (Coeficiente de Variação do Retorno sobre o Patrimônio Líquido). A utilização da relação defasada decorre do fato de que os retornos e as proxies de risco e retorno são estimados ex-ante e que o mercado realizará ajustes ex-post quando da divulgação das informações financeiras.

$$
\begin{aligned}
& \operatorname{Ret}_{i t}=\beta_{0}+\text { Beta }_{i t-1}+\sum_{i=1} \text { Controles }+\sum_{i=1} \text { Setor }+\sum_{i=1} \text { Ano }+\varepsilon_{i t} \\
& \operatorname{Ret}_{i t}=\beta_{0}+\sigma R O E_{i t-1}+\sum_{i=1}^{6} \text { Controles }+\sum_{i=1}^{5} \text { Setor }+\sum_{i=1}^{10} A n o+\varepsilon_{i t} \\
& \operatorname{ROE}_{i t}=\beta_{0}+\sigma R O E_{i t-1}+\sum_{i=1}^{6} \text { Controles }+\sum_{i=1}^{5} \text { Setor }+\sum_{i=1}^{10} \text { Ano }+\varepsilon_{i t}
\end{aligned}
$$

Como proxy de retorno, a partir de dados do mercado, utilizou-se o Retorno das Ações (Ret), conforme Campos et al. (2014) e Pimentel (2015). Os retornos das ações utilizados foram aqueles observados no trimestre subsequente à divulgação das informações contábeis (trimestrais), pois consiste no período em que o mercado realiza ajustes nos preços em decorrência da disponibilidade das informações contábeis (Penman, 2011; Penman \& Zhu, 2014). Como proxy de retorno contábil, utilizou-se ○ Retorno sobre o Patrimônio Líquido. Essa métrica foi usada no trabalho de Bowman (1980) e, posteriormente, em trabalhos nacionais e estrangeiros que buscaram analisar a existência do PB (Nickel \& Rodriguez, 2002; Silveira, 1990; Vieira, 2012).

Assim como Amorim et al. $(2012,2014)$ e Souza Filho et al. (2017), o proxy de risco de mercado se constituiu por meio do coeficiente beta ( $\beta$ ), que captura o nível de risco da firma em relação ao risco sistemático (de mercado). Os betas foram calculados trimestralmente em decorrência do fato de os dados contábeis estarem disponíveis na mesma base. Como proxy de risco contábil, utilizou-se o Coeficiente de Variação do ROE (oROE). Assim como em Silveira (1990) e Vieira (2012), que analisaram o PB no contexto brasileiro por meio de dados anuais, o oROE foi calculado para cada ano a partir da variabilidade dos ROEs ao longo dos trimestres em cada firma/ano. Esta estratégia de operacionalização considera que o mercado ajusta os preços e, portanto, os retornos das ações, à medida que os resultados trimestrais são disponibilizados ao mercado.

Para controlar outros fatores ambientais e que podem influenciar na relação entre o risco e o retorno, foram considerados o efeito Tamanho (Tam), o Nível de Endividamento (NivEnd), - Nível de Liquidez (ILI), o Setor Econômico (SegEcon), a adoção das Normas Internacionais (IFRS), os estágios do Ciclo de Vida da Firma, de acordo com Dickinson (2011), e $\circ$ Ano. As evidências anteriores sugerem que esses fatores podem influenciar nas relações observadas entre as proxies de risco-retorno utilizadas (Amorim et al., 2012; Andersen et al., 2007; Patel et al., 2018; Perobelli et al., 2016; Pimentel, 2015). As definições, a operacionalização das variáveis e os sinais esperados foram apresentados no Apêndice A.

\section{Análise de Dados e Discussão dos Resultados}

Inicialmente, analisou-se a estatística descritiva das variáveis utilizadas nos modelos (Tab.1). Nessa oportunidade, observou-se que o retorno médio das ações (Ret) no trimestre subsequente à publicação das demonstrações financeiras foi de $-0,5 \%$, variando entre $-65,4 \%$ e $68,0 \%$. Quando observado no trimestre a que se referem as demonstrações contábeis, o retorno médio foi de 0,001, com valor mínimo de $-0,956$, e máximo de 1,783. A despeito de haver uma diferença na média, ela não se mostrou significativa, mas sugere que o mercado faz ajustes nos preços após a

\begin{tabular}{|c|c|c|c|c|c|}
\hline & Obs. & $\mu$ & $\sigma$ & Min & Max \\
\hline \multicolumn{6}{|c|}{ Painel A - Variáveis quantitativas utilizadas nos modelos } \\
\hline $\operatorname{Ret}_{i+1}$ & 9,387 & $-0,005$ & 0,190 & $-0,654$ & 0,680 \\
\hline Retit $_{\text {it }}$ & 9,387 & 0,001 & 0,307 & $-0,956$ & 1,783 \\
\hline$\beta_{i+1}$ & 9,335 & 0,432 & 0,472 & $-0,853$ & 1,968 \\
\hline$\beta_{\mathrm{it}}$ & 9,387 & 0,447 & 0,488 & $-0,856$ & 1,976 \\
\hline $\mathrm{ROE}_{\mathrm{it}}$ & 9,387 & 0,077 & 0,457 & $-2,721$ & 2,209 \\
\hline$\sigma R O E_{i t}$ & 9,387 & 0,129 & 0,878 & $-5,757$ & 6,174 \\
\hline $\operatorname{Tam}_{\mathrm{it}}$ & 9,387 & 21,620 & 19,609 & 15,207 & 27,254 \\
\hline NivEndFin $_{i t}$ & 9,387 & 0,615 & 0,237 & 0,058 & 1,000 \\
\hline $\mathrm{IL}_{\mathrm{it}}$ & 9,387 & 0,602 & 0,793 & 0,000 & 6,071 \\
\hline \multicolumn{6}{|c|}{ Painel B - Variáveis categóricas utilizadas nos modelos } \\
\hline \multicolumn{6}{|c|}{ B1 - Estágios do Ciclo de Vida (Dickinson, 2011) } \\
\hline & Obs. & $\%$ & E.P & \multicolumn{2}{|c|}{$\begin{array}{c}\text { Logit } \\
\text { [95\% Inter. Conf.] }\end{array}$} \\
\hline Introdução & 985 & 0,105 & 0,003 & 0,099 & 0,111 \\
\hline Crescimento & 1931 & 0,206 & 0,004 & 0,198 & 0,214 \\
\hline Maturidade & 3714 & 0,396 & 0,005 & 0,386 & 0,406 \\
\hline
\end{tabular}
divulgação das demonstrações financeiras.

Tabela 1: Estatística descritiva das variáveis utilizadas nos modelos 


\begin{tabular}{|c|c|c|c|c|c|}
\hline Turbulência & 2260 & 0,241 & 0,004 & 0,232 & 0,250 \\
\hline Declínio & 497 & 0,053 & 0,002 & 0,049 & 0,058 \\
\hline \multicolumn{7}{|c|}{ B2- Segmentos Econômicos da B3 } \\
\hline Bens Industriais & 1.734 & 0,185 & 0,004 & 0,177 & 0,193 \\
\hline Consumo Cíclico & 3.096 & 0,330 & 0,005 & 0,320 & 0,339 \\
\hline Materiais Básicos & 1.076 & 0,115 & 0,003 & 0,108 & 0,121 \\
\hline $\begin{array}{c}\text { Petróleo, Gás e } \\
\text { Biocombustiveis }\end{array}$ & 259 & 0,028 & 0,002 & 0,024 & 0,031 \\
\hline Outros & 3.222 & 0,343 & 0,005 & 0,334 & 0,353 \\
\hline
\end{tabular}

Ret - Retorno de Mercado (trimestral) do trimestre subsequente à publicação das demonstrações contábeis; $\beta$ eta - Beta (trimestral) do ativo no trimestre corrente da publicação das demonstrações contábeis; ROE - Retorno sobre - Patrimônio Líquido; oROE - Coeficiente de Variação do ROE; TAM Logaritmo natural dos ativos totais, como proxy para o tamanho da empresa; NivEnd ${ }_{i t}$ - Nivel de endividamento da empresa; IL $L_{i t}$ - Índice de Liquidez Imediata da empresa. Todas as variáveis foram windsorizadas entre $1 \%$ e 99\% por trimestre/ano.

Fonte: Dados da pesquisa

No que se refere à média do Beta $(\beta)$, o proxy de risco específico apresentou média de 0,432 no trimestre subsequente à divulgação das demonstrações financeiras e variou entre $-0,853$ a 1,968. Por sua vez, no trimestre base das demonstrações financeiras, o Beta foi de 0,447, variando entre $-0,856$ a 1,976. Cumpre destacar que o Beta captura a volatilidade dos retornos das ações comparativamente ao retorno de mercado. Assim, quando analisado o ROE Retorno sobre o Patrimônio Líquido, verifica-se que a média foi de 0,077 com variação entre -2,721 e 2,209. Já no Coeficiente de Variação do ROE, proxy de risco a partir de dados contábeis, observou-se uma média de 0,129, valor mínimo de -5,757 e 6,174.

As variáveis Tamanho (Tam), Nível de Endividamento Financeiro e Liquidez apresentaram médias de 21,62, 0,615 e 0,602 , respectivamente. Nas três variáveis, verificou-se uma relativa dispersão, o que pode ser explicado pelo fato de a amostra ser composta por empresas de diversos segmentos econômicos e períodos (44 trimestres). A análise das variáveis categóricas evidencia que 70,70\% das observações estavam classificadas nos Estágios do Ciclo de Vida de Introdução (10,5\%), Crescimento (20,6\%) e Maturidade (39,60\%). Por sua vez, verificou-se que $66,7 \%$ das observações são relativas a empresas dos segmentos econômicos de Bens Industriais, Consumo Cíclico, Materiais Básicos e, Petróleo, Gás e Biocombustíveis. Os demais segmentos foram agrupados, pois não apresentaram, isoladamente, significância estatística nos modelos analisados.

Posteriormente, foram comparadas as médias dos retornos entre as empresas com menor e maior risco (Tab.2). Os resultados evidenciam que, em termos gerais, as empresas da amostra classificadas como de maior risco (Quartil superior do Beta e do Coeficiente de Variação do ROE) tenderam a apresentar maior retorno.

Tabela 2: Comparação das métricas de retorno entre os grupos com maior (Q4) e menor risco (Q1)

\begin{tabular}{|c|c|c|c|c|c|c|c|c|c|c|c|}
\hline & \multicolumn{4}{|c|}{ Menor Risco (Q1) } & \multicolumn{4}{|c|}{ Maior Risco (Q4) } & \multirow[b]{2}{*}{$\begin{array}{l}\text { Q4. } \\
\text { Q1 }\end{array}$} & \multirow[b]{2}{*}{ t } & \multirow[b]{2}{*}{ ks } \\
\hline & $\mu$ & $\circ$ & Min & $\operatorname{Max}$ & $\mu$ & o & Min & Max & & & \\
\hline \multicolumn{12}{|c|}{ Painel A: Proxy de risco Beta $(\beta) \mathrm{em} t$} \\
\hline $\operatorname{Ret}_{t+1}$ & $-0,017$ & 0,169 & $.0,588$ & 0,629 & 0,006 & 0,210 & $-0,606$ & 0,680 & 0,022 & *** & *** \\
\hline $\mathrm{Ret}_{\mathrm{t}}$ & 0,005 & 0,328 & $.0,956$ & 1,783 & 0,001 & 0,357 & $-0,956$ & 1,783 & $-0,005$ & NS & NS \\
\hline $\mathrm{ROE}_{\mathrm{i}}$ & 0,058 & 0,526 & $-2,721$ & 2,209 & 0,064 & 0,461 & $\cdot 2,721$ & 2,209 & 0,006 & NS & NS \\
\hline \multicolumn{12}{|c|}{ Painel A: Proxy de risco oROE em $t$} \\
\hline $\operatorname{Ret}_{t+1}$ & $-0,020$ & 0,219 & $-0,654$ & 0,647 & $-0,003$ & 0,188 & $-0,652$ & 0,593 & 0,017 & *** & *** \\
\hline Ret $_{\text {t }}$ & 0,006 & 0,532 & $-3,463$ & 5,829 & 0,015 & 0,420 & $-4,551$ & 4,393 & 0,008 & NS & $\cdots *$ \\
\hline ROE, & $.0,104$ & 0,769 & $-2,721$ & 2,209 & 0,079 & 0,320 & $\cdot 2,721$ & 2,209 & 0,183 & NS & $* * *$ \\
\hline
\end{tabular}

Nota: Menor Risco (Q1) Grupo de observações do Beta ou oROE no 1०. Quartil; Maior Risco (Q4) Grupo de observações do Beta ou oROE no 4. Quartil. B: Coeficiente Beta; oROE: Coeficiente de Variação do ROE. * **, *** Significativo estatisticamente aos níveis de 10\%, 5\% e 1\%. NS: Não Significativo. Realizou-se o Teste $t$ para diferença entre os grupos. Para a realização do teste, observou-se a homogeneidade das variâncias (ANOVA) entre os grupos previamente. Adicionalmente, como os retornos não apresentavam normalidade na distribuição (foram realizados os testes Shapiro-Wilk/Shapiro-Francia para normalidade), apesar de ser uma amostra grande, utilizou-se o teste Kruskall-Wallis (KS) para diferenças entre as medianas. Substituto, do test $t$ quando os pressupostos exigidos não são atendidos.

Fonte: Dados da pesquisa.

Contudo, não foram verificadas diferenças estatisticamente significativas em todas as comparações, mas os testes não paramétricos apresentaram-se significativos de forma mais consistente. Essas evidências consistem em indícios iniciais de que exista uma relação positiva entre o risco e o retorno das empresas listadas.

Na sequência, analisou-se a correlação entre as variáveis utilizadas nos modelos (Apêndice B). O que se verifica é que, em termos gerais, as correlações observadas entre as proxies de risco e retorno são fracas (abaixo de $50 \%$ ), mas positiva e estatisticamente significativas. Verificou-se, também, que essa relação tende a ser mais persistente nas relações defasadas. Por exemplo, o Beta do trimestre base das demonstrações financeiras está positivamente associado com ○ Retorno das ações no trimestre subsequente (após a divulgação das demonstrações financeira). Essa dinâmica foi observada tanto para relações intra proxies de risco/retorno, quanto entre elas. Estas evidências reforçam a relação positiva entre risco e retorno, inclusive, entre proxies mensuradas a partir de dados contábeis, embora ela ocorra com um efeito defasagem e não contemporâneo como os estudos sobre o PB tendem a utilizar (Nickel \& Rodriguez, 2002; Silveira, 1990; Vieira, 2012).

Posteriormente, foram analisadas as hipóteses 1, 2 e 3 a partir dos modelos de regressão, conforme evidencia a 
Tabela 3. Inicialmente, estimou-se um modelo geral com todo o período e, controlando-se o efeito da adoção das normas internacionais de contabilidade (IFRS), os modelos apresentaram-se estatisticamente significativos ao nível de $1 \%$.

Tabela 3: Estatística dos modelos de regressão com dados em painel

\begin{tabular}{|c|c|c|c|c|c|c|}
\hline \multicolumn{7}{|c|}{ Painel A - Estatística dos modelos para o período de 2008-2018 } \\
\hline \multirow[b]{2}{*}{ Intercepto } & \multicolumn{2}{|c|}{ 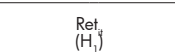 } & \multicolumn{2}{|c|}{$\begin{array}{l}\operatorname{Ret}_{\text {fit }} \\
\left(\mathrm{H}_{2}\right)\end{array}$} & \multicolumn{2}{|c|}{$\begin{array}{l}\mathrm{ROE}_{\text {it }} \\
\left(\mathrm{H}_{3}\right)^{\prime}\end{array}$} \\
\hline & $-0.185^{* * *}$ & (0.029) & $-0.138^{* * *}$ & $(0.026)$ & 0.206 & $(0.179)$ \\
\hline$\beta_{i+1}$ & $0.017^{* * *}$ & $(0.005)$ & & & & \\
\hline $\mathrm{OROE}_{t+1}$ & & & -0.001 & $(0.002)$ & $0.110^{* * *}$ & $(0.014)$ \\
\hline IFRS $_{\text {if }}$ & $0.165^{* * *}$ & (0.009) & $0.119^{* * *}$ & $(0.009)$ & $-0.091^{* * *}$ & (0.029) \\
\hline $\operatorname{TAM}_{t}$ & 0.002 & $(0.001)$ & $0.003^{* * *}$ & $(0.001)$ & 0.002 & (0.009) \\
\hline NivEnd & 0.015 & (0.010) & $-0.027^{* * *}$ & $(0.010)$ & $-0.116^{* *}$ & (0.067) \\
\hline $\mathrm{IL}_{\mathrm{it}}$ & $0.006^{*}$ & (0.003) & $0.006^{* *}$ & $(0.003)$ & 0.002 & $(0.010)$ \\
\hline INTR $_{t}$ & & & & & $-0.057^{* *}$ & (0.025) \\
\hline TURB $_{i t}$ & & & & & .0 .031 & $(0.021)$ \\
\hline $\mathrm{DECL}_{n}$ & $-0.024^{* * *}$ & (0.008) & $-0.030^{* * *}$ & $(0.007)$ & & \\
\hline Wald & \multicolumn{2}{|c|}{$722.40 * * *$} & \multicolumn{2}{|c|}{$619.57^{\prime * * *}$} & \multicolumn{2}{|c|}{$126.12^{* * *}$} \\
\hline Observaçōes & \multicolumn{2}{|c|}{9.387} & \multicolumn{2}{|c|}{9.387} & \multicolumn{2}{|c|}{9387} \\
\hline$R^{2} D|E| G$ & \multicolumn{2}{|c|}{9.39 | 12.79 | 9.52} & \multicolumn{2}{|c|}{$9.10|16.42| 9.42$} & \multicolumn{2}{|c|}{$5.37|15.07| 6.39$} \\
\hline No. De firmas & \multicolumn{2}{|c|}{292} & \multicolumn{2}{|c|}{292} & \multicolumn{2}{|c|}{292} \\
\hline Tipo de Painel & \multicolumn{2}{|c|}{ EA } & \multicolumn{2}{|c|}{ EA } & \multicolumn{2}{|c|}{ EA } \\
\hline $\begin{array}{l}\text { Controle de } \\
\text { Setor }\end{array}$ & \multicolumn{2}{|c|}{ Sim } & \multicolumn{2}{|c|}{ Sim } & \multicolumn{2}{|c|}{ Sim } \\
\hline $\begin{array}{c}\text { Controle de } \\
\text { Ano }\end{array}$ & \multicolumn{2}{|c|}{ Sim } & \multicolumn{2}{|c|}{ Sim } & \multicolumn{2}{|c|}{ Sim } \\
\hline
\end{tabular}

Painel B - Estatística dos modelos para o período de 2008-2009

\begin{tabular}{|c|c|c|c|c|c|c|}
\hline Intercepto & $0.243^{* * *}$ & $(0.012)$ & $-0.116^{* *}$ & $(0.059)$ & -0.120 & 0.237 \\
\hline$\beta_{\text {it-1 }}$ & $0.073^{* *}$ & $(0.012)$ & & & & \\
\hline OROE $_{\text {it }-1}$ & & & $-0.018^{* *}$ & $(0.009)$ & $0.071^{* *}$ & 0.035 \\
\hline $\begin{array}{c}\text { Demais } \\
\text { controles }\end{array}$ & \multicolumn{2}{|c|}{$\operatorname{Sim}$} & \multicolumn{2}{|c|}{ Sim } & \multicolumn{2}{c|}{ Sim } \\
\hline
\end{tabular}

Painel C - Estatística dos modelos para o período de 2010-2018

\begin{tabular}{|c|c|c|c|c|c|c|}
\hline Intercepto & -0.018 & $(0.030)$ & -0.044 & $(0.028)$ & 0.192 & $(0.152)$ \\
\hline$\beta_{i+1}$ & $0.014^{* * *}$ & $(0.005)$ & & & & \\
\hline${ }^{\prime} \mathrm{ROE}_{\mathrm{i}+1}$ & & & 0.001 & $(0.002)$ & $0.110^{* * *}$ & $(0.014)$ \\
\hline $\begin{array}{l}\text { Demais } \\
\text { controles }\end{array}$ & \multicolumn{2}{|c|}{ Sim } & \multicolumn{2}{|c|}{ Sim } & \multicolumn{2}{|c|}{ Sim } \\
\hline
\end{tabular}

respectivamente. Erros padrões robustos clusterizados nas firmas.

Fonte: Dados da pesquisa.

Em termos de capacidade de explicação, observou-se um $\mathrm{R}^{2}$ geral variando entre $6.69 \%$ e 9.52 . Considerando as hipóteses estabelecidas, verificou-se que existe uma relação positiva e estatisticamente significativa entre o risco $\left(\beta_{i t 1}\right)$ e o retorno (Ret.), mensurados com dados de mercado, o que reforça a hipótese 1. Quando analisada a associação entre a proxy de risco mensurada a partir de dados contábeis $\left(\sigma \mathrm{ROE}_{\mathrm{it}-\mathrm{f}}\right)$ e o retorno das ações, não foi verificada significância estatística, não se confirmando a relação positiva esperada; logo, a hipótese 2 não se confirmou. Verificou-se ainda, que a relação observada entre as proxies de risco e retorno, a partir de dados contábeis, confirma a hipótese 3 e reforça a expectativa de que quanto maior o risco, maior o retorno. Contudo, há que se destacar que essa relação é defasada, ou seja, o risco corrente $\left(\circ R O E_{i t-1}\right)$ está positivamente associado ao $\left(\mathrm{ROE}_{\mathrm{it}}\right)$ retorno subsequente.

Esses resultados convergem parcialmente com o observado por Amorim et al. (2012; 2014), e Penman e Zhu (2014), mas, dadas as limitações dos números contábeis, assim como observado em Mikosz et al. (2020) e Pimentel (2015), os retornos não apresentaram relações positivas e significativas com a proxy de risco, mensurada a partir de dados contábeis $\left(\sigma \mathrm{ROE}_{\mathrm{it}-1}\right)$.

De modo a se reduzir um potencial viés nos coeficientes em decorrência da mudança nas normas de contabilidade (IFRS), quando estimado com dados de todo o período, foram estimados os respectivos modelos por período (20082009 e 2010-2018). Os resultados demonstram que, no período de transição (2008-2009), as relações esperadas para as hipóteses 1 e 3 foram confirmadas, porém, para a hipótese 2, os coeficientes foram negativos e estatisticamente significativos. Esse resultado reforça evidências anteriores de que períodos com elevada incerteza prejudicam a previsibilidade dos lucros e, portanto, a relação esperada pode se inverter.

Destaca-se que, nos anos de 2008 e 2009, além de serem um período de transição, o mercado de capitais sofria os reflexos da Crise do Subprime de 2008. Além disso, sabe-se que muitas incertezas precificadas pelo mercado não podem ser reconhecidas nas demonstrações contábeis, em decorrência das restrições normativas. Quando estimado o período de 2010-2018, verifica-se que as hipóteses 1 e 3 foram novamente confirmadas e que o sinal esperado na hipótese 2 se tornou positivo, porém, não estatisticamente significativo. Esse resultado é interessante, pois reforça as evidências de que períodos de incertezas econômicas, políticas, sociais ou normativas podem prejudicar a capacidade preditiva dos números contábeis (Becerra \& Markarian, 2021; Ely, 2015; Muñoz et al., 2020).

A análise das variáveis de controle demonstra, ainda, que empresas maiores e com maior liquidez estão associadas a maiores retornos e que aquelas classificadas nos Estágios do Ciclo de Vida de Introdução e Declínio tendem a apresentar retorno das ações e contábil menor.

De modo a se obter evidências mais consistentes quanto à relação entre o risco e o retorno, utilizando-se proxies de mercado e a partir de números contábeis, estimou-se os modelos de regressão utilizando-se como proxies de risco os 
quartis do Beta $\left(\beta_{\mathrm{it}-1}\right)$ e do $\left(\sigma \mathrm{ROE}_{\mathrm{it}-1)}\right.$. Conforme se observa na Tabela 4, em termos gerais, os modelos foram estatisticamente significativos e os Coeficientes de Determinação geral aumentaram. Utilizando essa estratégia de operacionalização das proxies de risco, os modelos reforçaram a ideia de que o risco e o retorno estão positivamente associados, logo, as três hipóteses foram confirmadas.

Tabela 4: Estatística dos modelos de regressão com dados em painel (Quartis das proxies de risco)

\begin{tabular}{|c|c|c|c|c|c|c|}
\hline \multicolumn{7}{|c|}{ Painel A - Estatística dos modelos para o período de 2008-2018 } \\
\hline \multirow[b]{2}{*}{ Intercepto } & \multicolumn{2}{|c|}{$\begin{array}{l}\operatorname{Ret}_{4} \\
\left(H_{1}\right)\end{array}$} & \multicolumn{2}{|c|}{$\begin{array}{l}\operatorname{Ret}_{4} \\
\left(\mathrm{H}_{2}\right)\end{array}$} & \multicolumn{2}{|c|}{$\begin{array}{l}\mathrm{ROE}_{\mathrm{in}} \\
\left(\mathrm{H}_{3}\right)^{\prime \prime}\end{array}$} \\
\hline & $-0.120^{* * *}$ & $(0.029)$ & $-0.137^{* * *}$ & $(0.026)$ & 0.018 & $(0.142)$ \\
\hline$Q 2 \beta_{i+1}$ & $0.0111^{* *}$ & $(0.005)$ & & & & \\
\hline Q3 $\beta_{i+1}$ & 0.008 & $(0.005)$ & & & & \\
\hline$Q 4 \beta_{i=1}$ & $0.021^{* * *}$ & $(0.006)$ & & & & \\
\hline $\mathrm{Q}_{\mathrm{QROR}} \mathrm{E}_{i=1}$ & & & $0.0226 * * *$ & $(0.006)$ & $0.360^{* * *}$ & (0.029) \\
\hline $\mathrm{Q}_{0} \circ \mathrm{ROE}_{n+1}$ & & & $0.0162^{* * *}$ & $(0.006)$ & $0.347^{* * *}$ & $(0.030)$ \\
\hline $\mathrm{Q}_{0} \circ \mathrm{ROE} \mathrm{E}_{\mathrm{k}-1}$ & & & 0.00551 & $(0.006)$ & $0.365^{* * *}$ & (0.034) \\
\hline IFRS $_{\text {it }}$ & $0.119^{* * *}$ & $(0.009)$ & $0.121^{* * *}$ & $(0.009)$ & $-0.074^{* * *}$ & $(0.027)$ \\
\hline TAM $_{t}$ & 0.001 & $(0.001)$ & 0.00125 & $(0.001)$ & -0.004 & $(0.007)$ \\
\hline Nivend ${ }_{t t}$ & $-0.025^{* *}$ & $(0.010)$ & $-0.0214^{* *}$ & $(0.010)$ & -0.062 & $(0.055)$ \\
\hline $\mathrm{IL}_{\mathrm{it}}$ & $0.006^{* *}$ & $(0.003)$ & $0.00518^{*}$ & $(0.003)$ & .0 .004 & $(0.009)$ \\
\hline INTR $_{t}$ & & & & & $-0.046^{* *}$ & $(0.022)$ \\
\hline TURB $_{i t}$ & & & & & -0.019 & $(0.020)$ \\
\hline $\mathrm{DECL}_{\mathrm{t}}$ & $-0.030 * * *$ & $(0.008)$ & $-0.0271^{* * *}$ & $(0.007)$ & & \\
\hline Wald & & $717.19 * * *$ & & $34.60 * * *$ & & $246.08 * * *$ \\
\hline Observaçōes & & 9.387 & & 9.387 & & 9.387 \\
\hline$R^{2} D|E| G$ & $9.35 \mid 1$ & 3.26 | 9.52 & $9.12 \mid 21$ & 41 | 9.62 & 9.83 | 34. & $13 \mid 14.98$ \\
\hline No. de firmas & & 292 & & 292 & & 292 \\
\hline Tipo de Painel & & EA & & EA & & EA \\
\hline Controle de Setor & & Sim & & Sim & & Sim \\
\hline Controle de Ano & & Sim & & Sim & & Sim \\
\hline
\end{tabular}

Painel B - Estatística dos modelos para o período de 2008-2009

\begin{tabular}{|c|c|c|c|c|c|c|}
\hline Intercepto & $-0.105^{*}$ & $(0.062)$ & -0.081 & $(0.060)$ & 0.014 & 0.263 \\
\hline 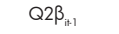 & $0.040^{* * *}$ & $(0.015)$ & & & & \\
\hline Q3 $\beta_{i+1}$ & $0.031^{* *}$ & $(0.014)$ & & & & \\
\hline Q4Bit-1 & $0.037^{* *}$ & $(0.017)$ & & & & \\
\hline $\mathrm{Q}^{\circ} \circ \mathrm{ROE}_{\mathrm{in}}$ & & & -0.012 & $(0.015)$ & $0.099 * * *$ & $(0.030)$ \\
\hline Q3oROE $E_{i, 1}$ & & & $-0.030^{* *}$ & $(0.015)$ & $0.092^{* * *}$ & (0.033) \\
\hline Q4oROE $E_{i, 1}$ & & & $-0.054^{* * *}$ & $(0.019)$ & 0.078 & $(0.050)$ \\
\hline Demais controles & & Sim & & Sim & & Sim \\
\hline
\end{tabular}

Painel C - Estatística dos modelos para o período de 2010-2018

\begin{tabular}{|c|c|c|c|c|c|c|}
\hline Intercepto & -0.022 & $(0.031)$ & $-0.048^{*}$ & (0.028) & -0.065 & $(0.153)$ \\
\hline$Q 2 \beta_{i=1}$ & 0.005 & $(0.006)$ & & & & \\
\hline Q3 $\beta_{n+1}$ & 0.005 & $(0.006)$ & & & & \\
\hline 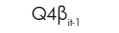 & $0.019^{* * *}$ & $(0.007)$ & & & & \\
\hline Q2oROE $E_{i=1}$ & & & $0.027^{* * *}$ & $(0.006)$ & $0.368^{* * *}$ & $(0.031)$ \\
\hline Q3oROE $E_{n-1}$ & & & $0.023^{* * *}$ & $(0.006)$ & $0.359^{* * *}$ & (0.032) \\
\hline Q4oROE $E_{n-1}$ & & & $0.014^{* *}$ & $(0.006)$ & $0.378^{* * *}$ & $(0.037)$ \\
\hline Demais controles & \multicolumn{2}{|c|}{ Sim } & \multicolumn{2}{|c|}{ Sim } & \multicolumn{2}{|c|}{ Sim } \\
\hline
\end{tabular}

Nota: Q2, Q3 e Q4 é se referem ao 2, 3 e 4 quartil das proxies de risco utilizadas $(\beta$, oROE)

$* * *, * *, *$ Estatisticamente significativos a $1 \%, 5 \%$ e 10\%, respectivamente. Erros padrões robustos clusterizados nas firmas.

Fonte: Dados da pesquisa.

Os resultados demonstraram ainda que o período de 2008 e 2009, como observado na Tabela 3, prejudica a análise da relação, pois, no contexto brasileiro, além de ser um período de transição das normas de contabilidade, o mercado de capitais mundial sofria os reflexos da crise do Subprime. Esses resultados reforçam as evidências obtidas por Campos et al. (2014), Muñoz et al. (2020) e Singh e Singh (2016). Já para o período 2010-2018, verificou-se que as três hipóteses foram confirmadas e que, à medida que o risco aumenta, o retorno tende a ser maior conforme prediz a literatura de finanças. A análise das variáveis de controle reforça que empresas maiores e com maior liquidez tendem a apresentar maiores retornos, e que aquelas com maior endividamento financeiro tendem a apresentar menores retornos.

\subsection{Testes de Robustez e Sensibilidade}

Para se verificar a robustez e a sensibilidade dos resultados, foram feitas estimações complementares, utilizando-se modelos com dados em painel com efeitos fixos e diversas especificações. Nesse caso, o controle de setor é o omitido, - que gera problema de viés de variável significativa, pois a literatura anterior reforma sistematicamente que a análise da relação do risco e retorno devem considerar aspectos setoriais e/ou mercadológicos (Andersen et al., 2007; Henkel, 2009). Os resultados reforçaram os achados apresentados nas Tabelas 3 e 4, porém, os modelos apresentaram estatísticas gerais mais frágeis ( $R^{2}$, Wald, etc). Além disso, em linha com o observado por Andersen et al. (2007) e Henkel (2009), verificou-se o efeito do desempenho abaixo do setor e observou-se uma associação negativa, com influência na relação entre o risco e o retorno das empresas da amostra. Quando controlado o desempenho superior, verificou-se que a relação positiva entre o risco e o retorno se confirma para as três hipóteses. Henkel (2009) observa que, quando existe uma distribuição assimétrica nos proxies de risco e retorno das firmas comparadas com a distribuição do setor, ou quando a previsibilidade dos retornos fica prejudicada (Val et al., 2014; Becerra \& Markarian, 2021), é possível que haja ruídos e que uma relação espúria negativa possa surgir quando relacionadas as proxies de risco e retorno.

\section{Considerações Finais}

O objetivo do presente estudo foi analisar a existência do Paradoxo de Bowman (PB) no contexto das empresas brasileiras listadas na Brasil, Bolsa, Balcão (B3). Para tanto, 
foram analisados os dados trimestrais de 292 empresas no período de 2008 a 2018, com o auxílio de estatística descritiva, teste de diferenças entre as médias e análise de regressão com dados em painel.

Os resultados confirmaram as hipóteses analisadas de que existe uma associação positiva entre risco e retorno, tanto a partir de dados contábeis, quanto de dados de mercado. Porém, essa relação é observada de forma mais consistente quando se considera o efeito defasagem, pois o mercado ajusta as expectativas de retorno a cada nova informação relevante para a precificação dos ativos. Verificou-se ainda, que a ideia de que existe um paradoxo quanto à relação risco e retorno é uma falácia, pois, a despeito das críticas e evidências de trabalhos que analisam o chamado "Paradoxo de Bowman" (Nickel \& Rodriguez, 2002), a inversão de sinal observada decorre, em parte, pelo fato de não se considerar que o processo de precificação de ativos é ex-ante.

Logo, o risco e o retorno, estimados hoje, não serão exatamente $\circ$ que se observará no futuro, portanto, não faz sentido analisar a associação entre proxies de risco e retorno ex-post e contemporâneas. Após a realização dos eventos econômicos, há que se compreender quais fatores influenciaram no erro de estimação, pois, a cada nova informação relevante disponível, os investidores vão ajustar suas expectativas quanto ao desempenho futuro das firmas.

Além disso, a despeito das evidências de que as informações contábeis são úteis para a precificação de ativos (Penman, 2011; Penman \& Zhu, 2014), é necessário levar em conta que os dados contábeis são mensurados a partir de parâmetros normativos que restringem $\circ$ reconhecimento de incertezas nas demonstrações financeiras. Portanto, sua capacidade preditiva será maior quando ajustadas pelo risco relacionado aos fluxos de caixa futuro da firma (Werneck et al., 2010; Konchitchki et al., 2016; Penman, 2016). Complementarmente, fatores ambientais, como a distribuição dos retornos das firmas em relação ao setor (Henkel, 2009) ou incertezas econômicas, políticas, sociais e normativas dificultam a preditividade dos retornos futuros, o que indica que as relações observadas ex-post podem não se confirmar, conforme observado (Becerra \& Markarian, 2021; Campos et al., 2014; Mikosz et al., 2020; Muñoz et al., 2020).

Os resultados observados fragilizam a ideia de que exista um "Paradoxo de Bowman", o qual, na perspectiva da literatura de finanças, não encontra respaldo lógico (Markowitz \& Dijk, 2008) e reforçam que os investidores esperam um retorno superior na medida em que o risco aumenta. Além disso, eles reforçam o papel da contabilidade nesse processo, mas evidenciam que fatores adversos, como o ambiente de incerteza econômica e/ou mudanças regulatórias, podem prejudicar a capacidade de os números contábeis explicarem os retornos das ações.

Os resultados contribuem com os diversos agentes econômicos que realizam análise e avaliação de empresas, como analistas de crédito, contadores, financistas e pesquisadores interessados no tema, pois demonstra que a proposta do PB no contexto brasileiro é falaciosa e que, provavelmente, os resultados observados em Silveira (1990) e Vieira (2012) decorrem do desenho de pesquisa utilizado, tendo resultado em relações espúrias não investigadas à época.

De forma específica, a literatura publicada nos principais periódicos nacionais não confirmou a associação positiva entre risco e retorno a partir de dados contábeis, os quais atribuem tal anomalia às características dos dados e ou fatores institucionais que fragilizam a aplicação dos modelos tradicionalmente utilizados (Mikosz et al., 2020; Muñoz et al., 2020; Perobelli et al., 2016; Pimentel, 2015).

Apesar dessas contribuiç̧ões, o estudo precisa avançar na explicação sobre em que condições, para além do ambiente de incerteza econômica, pode surgir uma relação espúria entre as métricas de risco e retorno. Sobre isso, Henkel (2009) destaca que a distribuição assimétrica das proxies de retorno em relação ao setor pode gerar tal ruído. Além disso, é possível que fatores como a competitividade, vieses de avaliação e julgamento prejudiquem tanto a estimação quanto o desempenho subsequente, logo, o expost na relação positiva entre o risco e o retorno não se confirmaria. A título de sugestão para pesquisas futuras, a análise desse pseudo-paradoxo, deve ser feita no sentido de se compreender com maior precisão, quais os mecanismos específicos que resultam em uma inversão nas correlações ex-post entre o risco e o retorno.

\section{Referências}

Amorim, A. L. G. C., Lima, I. S., \& Murcia, F. D.-R. (2012). Análise da relação entre as informações contábeis e o risco sistemático no mercado brasileiro. Revista Contabilidade \& Finanças, 23(60), 199-211. https://doi. org/10.1590/S1519-70772012000300005

Amorim, A. L. G. C., Lima, I. S., \& Pimenta Junior, T. (2014). Informação Contábil e o Beta de Mercado. Revista Universo Contábil, 10(4), 128-143. https://doi. org/10.4270/ruc.2014433

Andersen, T. J., Denrell, J., \& Bettis, R. A. (2007). Strategic responsiveness and Bowman's risk-return paradox. Strategic Management Journal, 28(4), 407-429. https:// 
doi.org/10.1002/smi.596

Araújo, R. C. C., \& Machado, M. A. V. (2018). Book-toMarket Ratio, return on equity and Brazilian Stock Returns. RAUSP Management Journal, 53(3), 324-344. https:// doi.org/10.1108/RAUSP-04-2018-001

Artuso, A. R., \& Chaves Neto, A. (2010). O uso de quartis para a aplicação dos filtros de Graham na Bovespa (19982009). Revista Contabilidade \& Finanças, 21(52), 1-20. https://doi.org/10.1590/S1519-70772010000100003

Barth, M. E., Li, K., \& McClure, C. G. (2021). Evolution in Value Relevance of Accounting Information. Stanford University Graduate School of Business Research Paper No. 17(24), 17-24. https://dx.doi.org/10.2139/ssrn.2933197

Ball, R., \& Brown, P. (1968). An Empirical Evaluation of Accounting Income Numbers. Journal of Accounting Research, 6(2), 159-178. https://doi. org/10.2307/2490232

Becerra, M., \& Markarian, G. (2021). Why Are Firms with Lower Performance More Volatile and Unpredictable? A Vulnerability Explanation of the Bowman Paradox. Organization Science, 32(25), 1149-1390. https://doi. org/10.1287/orsc.2021.1429

Beaver, W. H. (1968). The Information Content of Annual Earnings Announcements. Journal of Accounting Research, 6, 67-92. https://doi.org/10.2307/2490070

Bortoluzzo, A. B., Minardi, A. M. A. F., \& Passos, B. C. F. (2014). Analysis of multi-scale systemic risk in Brazil's financial market. Revista de Administração, 49(2), 240250. https://doi.org/10.5700/rausp1143

Bowman, E. H. (1980). A risk/return paradox for strategic management. 46. Disponível em: https:// dspace.mit.edu/bitstream/handle/1721.1/48928/ riskreturnparado00bowm.pdf?sequ. Acessado $31 / 10 / 2021$

Campos, O. V., Lamounier, W. M., \& Bressan, A. A. (2014). Previsão de Retornos e Fundamentos Contábeis em Período de Crise Mundial: Um estudo de carteiras utilizando vetores autoregressivos. Revista Universo Contábil, 10(4), 27-44. https://doi.org/10.4270/ruc.2014428

Chen, J. M. (2017). Econophysics and Capital Asset Pricing. Springer International Publishing. https://doi. org/10.1007/978-3-319-63465-4
Chiang, T. C., Li, H., \& Zheng, D. (2015). The intertemporal risk-return relationship: Evidence from international markets. Journal of International Financial Markets, Institutions and Money, 39, 156-180. https://doi.org/10.1016/j. intfin.2015.06.003

Christensen, M., Knudsen, T., Nash, U. W., \& Stieglitz, N. (2020). Industry competition and firm conduct: Joint determinants of RISK-RETURN relations. Strategic Management Journal, 41(12), 2315-2338. https://doi. org/10.1002/smi.3184

Dickinson, V. (2011). Cash Flow Patterns as a Proxy for Firm Life Cycle. The Accounting Review, 86(6), 19691994. https://doi.org/10.2308/accr-10130

Dimic, N., Orlov, V., \& Piljak, V. (2015). The political risk factor in emerging, frontier, and developed stock markets. Finance Research Letters, 15, 239-245. https://doi. org/10.1016/i.frl.2015.10.007

Ely, R. A. (2015). Volatility Spillovers and the Risk-Return Relation Between Stock and Foreign Exchange Markets in Brazil. Latin American Business Review, 16(4), 305-325. https://doi.org/10.1080/10978526.2015.1114868

Fabozzi, F. J., Gupta, F., \& Markowitz, H. M. (2002). The Legacy of Modern Portfolio Theory. The Journal of Investing, 11(3), 7-22. https://doi.org/10.3905/joi.2002.319510

Fama, E. F. (1970). Efficient Capital Markets: A Review of Theory and Empirical Work. The Journal of Finance, 25(2), 383-417. https://doi.org/10.2307/2325486

Fernandez, P., Bañuls, S., \& Fernandez Acin, P. (2021). Survey: Market Risk Premium and Risk-Free Rate used for 88 countries in 2021. SSRN - Social Science Research Network, 1-17. https://doi.org/10.2139/ssrn.3861152

Fiegenbaum, A., \& Thomas, H. (1988). Attitudes Toward Risk and The Risk-Return Paradox: Prospect Theory Explanations. Academy of Management Journal, 31(1), 85-106. https://doi.org/10.5465/256499

Giner, B., \& Reverte, C. (2006). The Risk-Relevance of Accounting Data: Evidence from the Spanish Stock Market. Journal of International Financial Management and Accounting, 17(3), 175-207. https://doi.org/10.1111/ j.1467-646X.2006.00126.x

Gospodinov, N., Kan, R., \& Robotti, C. (2017). Spurious Inference in Reduced-Rank Asset-Pricing 
Models. Econometrica, 85(5), 1613-1628. https://doi. org/10.3982/ECTA13750

Gregoire, V., \& Martineau, C. (2021). How Is Earnings News Transmitted to Stock Prices? SSRN - Social Science Research Network, 1-47. https://dx.doi.org/10.2139/ ssrn.3060094

Henkel, J. (2009). The risk-return paradox for strategic management: Disentangling true and spurious effects. Strategic Management Journal, 30(3), 287-303. https:// doi.org/10.1002/smi.734

Holder, A. D., Petkevich, A., \& Moore, G. (2016). Does managerial myopia explain Bowman's Paradox? American Journal of Business, 31(3), 102-122. https://doi. org/10.1108/AJB-04-2015-0008

Jia, N., Rai, A., \& Xu, S. X. (2020). Reducing Capital Market Anomaly: The Role of Information Technology Using an Information Uncertainty Lens. Management Science, 66(2), 979-1001. https://doi.org/10.1287/mnsc.2018.3235

Johnstone, D. J. (2021). Accounting information, disclosure, and expected utility: Do investors really abhor uncertainty? Journal of Business Finance \& Accounting, 48(1-2), 3-35. https://doi.org/10.1111/ibfa.12518

Kahneman, D., \& Tversky, A. (1979). Prospect theory: An analysis of decision under risk. Econometrica: Journal of the Econometric Society, 263-291.

Kliger, D., \& Tsur, I. (2011). Prospect Theory and RiskSeeking Behavior by Troubled Firms. Journal of Behavioral Finance, 12(1), 29-40. https://doi.org/10.1080/1542756 0.2011 .555028

Konchitchki, Y., Luo, Y., Ma, M. L. Z., \& Wu, F. (2016). Accounting-based downside risk, cost of capital, and the macroeconomy. Review of Accounting Studies, 21(1), 1-36. https://doi.org/10.1007/s11142-015-9338-7

Kothari, S. P. (2001). Capital markets research in accounting. Journal of Accounting and Economics, 31(1), 105-231.

Lewellen, J. (2010). Accounting anomalies and fundamental analysis: An alternative view. Journal of Accounting and Economics, 50(2-3), 455-466. https://doi.org/10.1016/i. jacceco.2010.09.007

Lintner, J. (1965). The Valuation of Risk Assets and the
Selection of Risky Investments in Stock Portfolios and Capital Budgets. The Review of Economics and Statistics, 47(1), 13-37. https://doi.org/10.2307/1924119

Lopes, A. B., \& Alencar, R. C. (2010). Disclosure and cost of equity capital in emerging markets: The Brazilian case. The International Journal of Accounting, 45(4), 443-464. https://doi.org/10.1016/j.intacc.2010.09.003

Lyle, M. R., Callen, J. L., \& Elliott, R. J. (2013). Dynamic risk, accounting-based valuation and firm fundamentals. Review of Accounting Studies, 18(4), 899-929. https:// doi.org/10.1007/s11142-013-9227-x

Marinho, K. B. A., Menezes, T. A., Lagioia, U. C. T., Carlos Filho, F. A., \& Lemos, L. V. (2013). Indicadores Financeiros e Contábeis que Influenciam a Tomada de Decisão do Investidor na Elaboração de uma Carteira de Ações e na Determinação do Nível de Risco. Revista Evidenciação Contábil \& Finanças, 1(2), 52-68. https://doi.org/DOI: $10.18405 /$ recfin20130204

Markowitz, H.M. (1952). Portfolio Selection. The Journal of Finance, 7(1), 77-91. https://doi.org/10.2307/2975974

Markowitz, H. M., \& Dijk, E. V. (2008). Risk-return analysis. In Handbook of Asset and Liability Management, 139197. Elsevier. https://doi.org/10.1016/B978-0444532480.50010-1

Martinez, A. L., \& Castro, M. A. R. (2011). The smoothing hypothesis, stock returns and risk in Brazil. BAR Brazilian Administration Review, 8(1), 1-20. https://doi. org/10.1590/S1807-76922011000100002

Mikosz, K., Macedo, M., \& Roma, C. (2020). Expected Return, Firm Fundamentals, and Aggregate Systemic Risk: An Analysis for the Brazilian Market using an Accounting-Based Valuation Model. Review of Business Management, 22(2), 271-289. https://doi.org/10.7819/ rbgn.v22i2.4056

Modigliani, F., \& Miller, M. H. (1963). Corporate Income Taxes and the Cost of Capital: A Correction. The American Economic Review, 53(3), 433-443.

Muñoz, R., Pablo, J., Salinero, Y., \& Peña, I. (2020). Risk measures and the risk-return paradox: An analysis in the context of the economic crisis. Review of Business Management, 22(2), 348-362. https://doi.org/10.7819/ rbgn.v22i2.4049 
Nickel, M. N., \& Rodriguez, M. C. (2002). A review of research on the negative accounting relationship between risk and return: Bowman's paradox. Omega, 30(1), 1-18. https://doi.org/10.1016/S0305-0483(01)00055-X

O'Regan, P. (2015). Financial Information Analysis (0 ed). Routledge. https://doi.org/10.4324/9781315848372

Paolone, F. (2020). Accounting, Cash Flow and Value Relevance. Springer International Publishing. https://doi. org/10.1007/978-3-030-50688-9

Patel, P. C., Li, M., \& Park, H. D. (2018). A replication of Bowman's paradox across 28 countries. Journal of Innovation \& Knowledge, 3(3), 128-142. https://doi. org/10.1016/i.jik.2016.12.006

Penman, S. (2011). Accounting for Risk and Return in Equity Valuation. Journal of Applied Corporate Finance, 23(2), 50-58. https://doi.org/10.1111/i.17456622.2011.00326.x

Penman, S. (2016). Valuation: Accounting for Risk and the Expected Return: ACCOUNTING, risk, and return. Abacus, 52(1), 106-130. https://doi.org/10.1111/abac.12067

Penman, S. H., \& Zhu, J. L. (2014). Accounting Anomalies, Risk, and Return. The Accounting Review, 89(5), 18351866. https://doi.org/10.2308/accr-50799

Perobelli, F. F. C., Famá, R., \& Sacramento, L. C. (2016). Return and Liquidity Relationships on Market and Accounting Levels in Brazil. Revista Contabilidade \& Finanças, 27(71), 259-272. https://doi.org/10.1590/1808$057 \times 201601530$

Pimentel, R. C. (2015). Lucros Inesperados, Retorno das Ações e Risco no Mercado de Capitais Brasileiro. Revista Contabilidade \& Finanças, 26(69), 290-303. https://doi. org/10.1590/1808-057x201501270

Salvador, E. (2012). The Risk-Return Trade-Off in Emerging Markets. Emerging Markets Finance and Trade, 48(6), 106128. https://doi.org/10.2753/REE1540-496X480606

Sampaio, F., Lopes, I., \& Gomes, L. (2018). Risco, Retorno e Equlíbrio na Bolsa de Valores Portuguesa. Portuguese Journal of Finance, Management and Accounting, 4(8), 69-100.

Sharpe, W. F. (1964). Capital asset prices: A theory of market equilibrium under conditions of risk. The Journal of finance, 19(3), 425-442.

Shum, W. C., \& Tang, G. Y. N. (2010). Risk-Return Characteristics: Comparison of China's Stock Market and Three Other Emerging Markets. The Chinese Economy, 43(5), 15-31. https://doi.org/10.2753/CES1097. 1475430502

Silveira, J. A. G. (1990). Risco versus retorno a partir de dados contábeis de empresas brasileiras: Uma contribuição empírica. (Tese de Doutorado) FGV EAESP - Escola de Administração de Empresas de São Paulo. http://hdl.handle.net/10438/4495

Singh, A., \& Singh, M. (2016). Risk-Return Relationship in BRIC Equity Markets: Evidence from Markov Regime Switching Model with Time-varying Transition Probabilities. Metamorphosis: A Journal of Management Research, 15(2), 69-78. https://doi.org/10.1177/0972622516675814

Singh, A., \& Singh, M. (2017). Intertemporal risk-return relationship in BRIC equity markets after the US financial crisis. International Journal of Law and Management, 59(4), 547-570. https://doi.org/10.1108/IJLMA-12-2015-0065

Souza Filho, E. A., Albuquerque, J. R., Anjos, L. C. M., \& Rodrigues, R. N. (2017). Assimetria Informacional no Mercado de Capitais Brasileiro: Os relatórios contábeis são capazes de reduzir o risco de investimento? Revista de Contabilidade do Mestrado em Ciências Contábeis da UERJ, 22(2), 39-53.

Val, F. de F., Pinto, A. C. F., \& Klotzle, M. C. (2014). Volatilidade e Previsão de Retorno com Modelos de Alta Frequência e GARCH: Evidências para $\circ$ Mercado Brasileiro. Revista Contabilidade \& Finanças, 25(65), 189-201. https://doi.org/10.1590/S151970772014000200008

Vieira, M. V. (2012). A relação risco-retorno e o paradoxo de Bowman: Uma investigação em empresas brasileiras. (Tese de Doutorado) CEPEAD - Centro de Pós-graduação e Pesquisa em Administração da Universidade Federal de Minas Gerais. http://hdl.handle.net/1843/BUOS$98 \mathrm{MH} 5 \mathrm{H}$

Werneck, M. A., Nossa, V., Broedel Lopes, A., \& J. C. Teixeira, A. (2010). Estratégia de investimentos baseada em informações contábeis: Modelo residual income valuation - Ohlson versus r-score - Piotroski. Advances in Scientific and Applied Accounting, 3(2), 141-164. https:// doi.org/10.14392/ASAA.2010030201 
Apêndice A. Operacionalização das variáveis utilizadas nos modelos

\begin{tabular}{|c|c|c|}
\hline Variável & Descrição & Operacionalização \\
\hline $\operatorname{Ret}_{i t}$ & $\begin{array}{l}\text { Retorno das Ações } \\
\text { Apurado Trimestralmente }\end{array}$ & 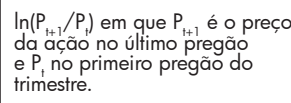 \\
\hline $\mathrm{ROE}_{\mathrm{it}}$ & $\begin{array}{l}\text { Retorno sobre o PL no } \\
\text { Período } \dagger\end{array}$ & $\begin{array}{l}\mathrm{LL} / \mu \mathrm{PL} \text { em } \mu \text { foi calculada entre } \\
\text { os trimestres. }\end{array}$ \\
\hline Beta $_{i t}$ & $\begin{array}{l}\text { Coeficiente Beta do } \\
\text { Trimestre }\end{array}$ & $\begin{array}{l}\left(\text { Covv }\left(r_{r}, r_{m}\right) /\left(V a r\left(r_{m}\right) \text { em que } r_{1} \text { é é }\right.\right. \\
\text { o retorno diário da empresa e } \\
r_{m^{\prime}} \text { o diário do IBOVESPA. }\end{array}$ \\
\hline$\sigma \mathrm{ROE}_{\mathrm{it}}$ & $\begin{array}{l}\text { Coeficientes de Variação } \\
\text { do ROE }\end{array}$ & $\begin{array}{l}\sigma R O E / \mu R O E \text { em que } \sigma \text { e } \mu \\
\text { foram calculados em cada ano } \\
\text { utilizando-se dados trimestrais. }\end{array}$ \\
\hline $\operatorname{Tam}_{\text {it }}$ & Tamanho da Firma & $\begin{array}{l}\text { Logaritmo natural dos ativos } \\
\text { totais }\end{array}$ \\
\hline NivEnd $_{\text {it }}$ & Nível de Endividamento & (Passivo Total)/(Ativo Total) \\
\hline $\mathrm{IL}_{\mathrm{hit}}$ & $\begin{array}{l}\text { Índice de Liquidez } \\
\text { Imediata }\end{array}$ & Disponível/(Ativo Circulante) \\
\hline IFRSit & IFRS & $\begin{array}{l}\text { Variável dummy que assume } \\
\text { valor } 1 \text { para o período pós- } \\
\text { IFRS e } 0 \text { para o pré-IFRS. }\end{array}$ \\
\hline CVida $_{i t}$ & Estágio do Ciclo de Vida & $\begin{array}{l}\text { Variável dummy que assume } \\
\text { valor } 1 \text { para o i-ésimo estágio } \\
\text { de Ciclo de Vida de Dickson } \\
\text { (2011) e } 0 \text { para os demais. }\end{array}$ \\
\hline SegEcon & Segmento Econômico & $\begin{array}{l}\text { SegEcon_it: Variável dummy } \\
\text { que assume valor } 1 \text { para o o } \\
\text { i-ésimo segmento econômico } \\
\text { da B3 e } 0 \text { para os demais. }\end{array}$ \\
\hline Trim $_{\text {it }}$ & Trimestre & $\begin{array}{l}\text { Variável dummy que assume } \\
\text { valor } 1 \text { para o i-ésimo trimestre } \\
\text { e } 0 \text { para os demais }\end{array}$ \\
\hline
\end{tabular}

Fonte: Bowman (1980), Figenbaum \& Thomas (1986), Silveira (1990), Nickel \& Rodriguez, (2002), Henkel (2009), Vieira (2012), Sampaio et al. (2018).
Apêndice B. Matriz de correlação entre as variáveis utilizadas nos modelos

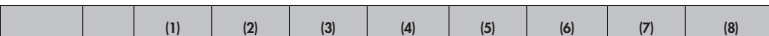

\begin{tabular}{|c|c|c|c|c|c|c|c|c|c|}
\hline & & (1) & (2) & (3) & (4) & (5) & (6) & (7) & (8) \\
\hline Ret $_{t}$ & (1) & 1.000 & & & & & & & \\
\hline $\operatorname{Ret}_{i+1}$ & (2) & $0.043 \cdots$ & 1.000 & & & & & & \\
\hline$\beta_{z}$ & (3) & -0.015 & $0.040 \cdots$ & 1.000 & & & & & \\
\hline$\beta_{z+1}$ & (4) & 0.024 & 0.001 & $0.561 \cdots$ & 1.000 & & & & \\
\hline $\mathrm{ROA}_{t}$ & (5) & 0.014 & $0.050^{\circ} \cdots$ & $0.058 \cdots$ & $0.053^{\cdots} \cdots$ & 1.000 & & & \\
\hline${ }^{O R O A} A_{t}$ & (6) & $0.027 \cdots$ & $0.034^{* \cdots}$ & .0 .013 & .0 .014 & $0.224 \cdots$ & 1.000 & & \\
\hline $\mathrm{ROE}_{\mathrm{in}}$ & (7) & 0.014 & $0.023^{* *}$ & .0 .002 & .0 .002 & $0.115 \cdots$ & $0.098 \cdots$ & 1.000 & \\
\hline $\mathrm{oROE}_{\mathrm{it}}$ & (8) & $0.021^{* *}$ & .0 .001 & $.0 .022^{* *}$ & $.0 .020^{\circ}$ & $0.052 \cdots$ & $0.592 \cdots$ & $0.235 \cdots$ & 1.000 \\
\hline $\operatorname{Tam}_{\mathrm{A}}$ & (9) & .0 .014 & $0.027 \cdots$ & $0.371 \cdots$ & $0.381 \cdots$ & $0.307 \cdots$ & $0.107 \cdots$ & $0.034 \cdots$ & 0.007 \\
\hline NivEnd $_{i t}$ & (10) & 0.007 & $.0 .045 \cdots$ & $.0 .032 \%$ & $-0.035 \%$ & $-0.417 \cdots$ & $-0.142 * \cdots$ & $.0 .047 \cdots$ & $.0 .049 \cdots$ \\
\hline $\mathrm{IL}_{\mathrm{it}}$ & (11) & 0.0104 & $0.037 * *$ & 0.0137 & $0.025 \cdots$ & $0.197 \cdots$ & $0.064 \cdots$ & $0.036 \cdots$ & $0.028 \cdots$ \\
\hline MAT ${ }_{a}$ & (12) & $0.017^{*}$ & $0.022^{* *}$ & .0 .013 & -0.010 & $0.128^{*} \cdots$ & 0.016 & $0.048 \cdots$ & 0.007 \\
\hline $\mathrm{INTR}_{\mathrm{f}}$ & (13) & .0 .010 & $.0 .023^{* *}$ & 0.002 & 0.007 & $-0.156 \cdots$ & $0.065 \%$ & $.0 .061 \cdots$ & $.0 .031 \cdots$ \\
\hline CRESC & (14) & -0.007 & .0 .005 & $0.026^{*}$ & $0.0222^{*}$ & $0.069 \%$ & $0.032 \%$ & .0 .002 & 0.009 \\
\hline TURB, & (15) & .0 .003 & $0.017^{*}$ & $.0 .019^{*}$ & .0 .013 & $.0 .042 \cdots$ & 0.002 & 0.008 & 0.008 \\
\hline DECL, & (16) & .0 .008 & $0.041^{\cdots \cdots}$ & 0.015 & .0 .004 & .0 .111 & 0.007 & $.0 .032 \%$ & .0 .001 \\
\hline $\mathrm{BI}_{\mathrm{i}}$ & (17) & .0 .002 & $.0 .025^{* *}$ & $-0.053 * \cdots$ & $.0 .059 \cdots$ & $-0.022^{* *}$ & $0.026^{* *}$ & $0.026^{*}$ & $0.018^{*}$ \\
\hline $\mathrm{COM}_{\mathrm{i}}$ & (18) & 0.011 & 0.002 & $0.045 \cdots$ & $0.041 \cdots$ & 0.016 & 0.006 & .0 .006 & .0 .014 \\
\hline $\mathrm{CC}_{\mathrm{i}}$ & (19) & .0 .004 & .0 .000 & $0.057 \cdots$ & $0.053^{\cdots} \cdots$ & .0 .013 & 0.009 & .0 .012 & .0 .006 \\
\hline$M B_{i}$ & (20) & 0.008 & 0.001 & $0.074 \cdots$ & $0.077 \cdots$ & -0.013 & 0.001 & $.0 .032 \cdots$ & $0.018^{*}$ \\
\hline \multirow[t]{2}{*}{$P G B_{1}$} & (21) & $.0 .030^{* *}$ & .0 .017 & $0.070^{\circ} \cdots$ & $0.066 * \cdots$ & $.0 .114 \cdots$ & $-0.030 \%$ & 0.006 & 0.001 \\
\hline & & (9) & (10) & (11) & (12) & (13) & (14) & (15) & (16) \\
\hline $\operatorname{Tam}_{\mathrm{H}}$ & (9) & 1.000 & & & & & & & \\
\hline NivEnd & (10) & $.0 .040^{* *}$ & 1.000 & & & & & & \\
\hline $\mathrm{IL}_{\mathrm{it}}$ & (11) & $-0.014^{*} *$ & $-0.474 * *$ & 1.000 & & & & & \\
\hline MAT, & (12) & $0.059 \cdots$ & $0.117 \cdots$ & .0 .0005 & 1.000 & & & & \\
\hline $\mathbb{I N T R}_{\mathrm{a}}$ & (13) & $-0.107 * \cdots$ & $0.127^{* * *}$ & $.0 .087 \cdots$ & $-0.277 \cdots$ & 1.000 & & & \\
\hline CRESC $_{\text {it }}$ & (14) & $0.129^{* * *}$ & .0 .009 & $0.081 \cdots$ & $.0 .412^{*} \cdots$ & $.0 .174 \cdots$ & 1.000 & & \\
\hline TURB, & (15) & $-0.094 \cdots$ & $0.032^{* \cdots}$ & 0.008 & $.0 .456 \cdots$ & $.0 .193 \ldots$ & $0.287 \cdots$ & 1.000 & \\
\hline DECL, & (16) & $0.037^{*} \cdot$ & $0.037^{*+*}$ & $.0 .042^{*} \cdots$ & $.0 .191 \ldots$ & $.0 .081 \cdots$ & $-0.120^{\circ} \cdots$ & $0.133 \cdots$ & 1.000 \\
\hline $\mathrm{BI}_{\mathrm{i}}$ & (17) & $.0 .193^{* *}$ & $0.084^{* * *}$ & .0 .002 & .0 .007 & $-0.043 \cdots$ & $0.040 \cdots$ & 0.000 & 0.004 \\
\hline $\mathrm{COM}_{\mathrm{i}}$ & (18) & $0.134 * \cdots$ & .0 .015 & 0.001 & $0.031 \cdots$ & 0.003 & 0.007 & 0.016 & $-0.029 \cdots$ \\
\hline $\mathrm{CC}_{\mathrm{i}}$ & (19) & $-0.087 \cdots$ & $0.017^{*}$ & $.0 .057 \cdots$ & $-0.055 \cdots$ & $0.093 \cdots$ & $0.101 \cdots$ & $0.054 \cdots$ & $0.072^{\cdots} \cdots$ \\
\hline$M B_{i}$ & (20) & $0.062 \cdots$ & $.0 .028 \cdots$ & $0.058 \cdots$ & $0.045 * \cdots$ & $-0.034 * \cdots$ & 0.014 & 0.004 & $-0.034 \cdots$ \\
\hline \multirow[t]{2}{*}{$P G B_{i}$} & (21) & 0.087 & 0.010 & $0.074 \cdots$ & $.0 .034 \cdots$ & $.0 .049 \cdots$ & $0.033^{\cdots} \cdots$ & 0.016 & $0.050^{* \cdots}$ \\
\hline & & (17) & (18) & (19) & (20) & (21) & & & \\
\hline $\mathrm{Bl}_{\mathrm{i}}$ & (17) & 1.000 & & & & & & & \\
\hline $\mathrm{COM}_{\mathrm{i}}$ & (18) & $.0 .059 \cdots$ & 1.000 & & & & & & \\
\hline $\mathrm{CC}_{\mathrm{B}}$ & (19) & $.0 .334 \%$ & $.0 .087 \cdots$ & 1.000 & & & & & \\
\hline$M B_{i}$ & (20) & $.0 .171 \cdots$ & $.0 .044^{\cdots \cdots}$ & $-0.252 \cdots$ & 1.000 & & & & \\
\hline$P G B$ & (21) & $.0 .080^{*} \cdots$ & $.0 .021 \%$ & $0.118^{\mu}$ & $.0 .061 \cdots$ & 1.000 & & & \\
\hline
\end{tabular}

Fonte: Bowman (1980), Figenbaum \& Thomas (1986), Silveira (1990), Nickel \& Rodriguez, (2002), Henkel (2009), Vieira (2012), Sampaio et al. (2018). 